\title{
The Relationship of Personality and Trait Anxiety between Male and Female Volleyball Players
}

\section{${ }^{1}$ Asterios Patsiaouras ${ }^{*},{ }^{2}$ Maria Chatzidimitriou, ${ }^{3}$ Konstantinos Charitonidis, ${ }^{1}$ Athina Giota, ${ }^{1}$ Dimitrios Kokaridas}

${ }^{1}$ University of Thessaly/DPESS, Trikala, Karies, Greece. ${ }^{2}$ Alexandre Technological Educational Institute of Thessaloniki, Thessaloniki, Greece. ${ }^{3}$ Aristotle Univeristy of Thessaloniki/DPESS, Thessaloniki, Greece.

\begin{abstract}
Objectives. The purpose of the study was to examine possible correlations and differences of personality and trait anxiety between male and female volleyball players. Methods. The sample consisted of 79 Division A \& C volleyball athletes (35 men and 44 women). Personality factors were investigated with the use of IPIP (International Personality Item Pool), whereas for trait anxiety the STAI - X2 (State - Trait Anxiety Inventory) questionnaire was used. Results. Statistically important differences were noticed between male and female volleyball players regarding the factors of extraversion, agreeableness, and emotional stability. In the remainder examined factors, that is, trait anxiety, consciousness and intellectual ability-imagination, no statistically important differences were noticed. A differentiation was also noticed regarding the relationship of factors when gender was selected as a criterion. Conclusion. The results reveal that male athletes were influenced to a different degree on personality factors as compared to female athletes. Further research is needed to investigate differences between the two genders by using samples from other team and individual sports.
\end{abstract}

KEY WORDS: Personality, Big 5, Anxiety, Volleyball.

\section{INTRODUCTION}

Until now, there is not a commonly accepted definition of personality, as the characteristics, structure, way of development, and different behaviors caused by the psychological meaning of personality are manifested in a unique way for each person (1). As a general tendency, each researcher defines personality based on the influence of each theory or approach that the researcher follows (psychodynamic, behaviorism, client-centered etc.).

Nowadays, personality is a factor that not only affects the life of a person significantly, but also defines ones success, career, happiness, and relationships in life, all factors that constitute personality based on personal characteristics that are defined as "the big 5 factors" (2). Researches of personality are more focused on theories that attempt to explain situations, because such theories provide more flexibility on the clarification of the interaction between the person and the environmental factors (3-6). On the other hand, the model of 5 factors strives to incorporate senses regarding the predisposition of a person $(5,7)$.

Adherents of the 5 factors theory support that we are able to understand personality via 5

*. Corresponding Author:

Asterios Patsiaouras

E-mail: spats@pe.uth.gr 
general factors of predisposition, which are: 1) extraversion (cordiality, sociability, confidence, activity, research of emotions, positive emotions), 2) neuroticism (anxiety, aggression, sadness, shyness, vulnerability, impulsiveness), 3) intellectual ability - imagination (imagination, openness to experience, esthete, emotions, intensity, ideas, principles, 4) agreeableness (confidence, compliance, sensitization, frankness, altruism, humility), and 5) consciousness (will, reliability, assiduity, consistent with authorities, ambitions, persistence, thoughtfulness) (8-10).

According to Costa and McCrae (1997) "the big 5 factors" are the same both for different civilizations and for different languages (2). This, in turn, proves their globalization, with the score and self-evaluation that a person achieves remaining stable throughout life. Nevertheless, some researchers do not support the globalization of the 5 factors, as the model is based on an unauthorized selection process through interrelations of empirical factors (11, 12).

The above model was applied as a theoretical framework by many researchers to explain the meaning of personality, which was incorporated into their questionnaires. According to Hofstee, De Raad, and Goldberg (1992), studies that derive from 3 domains contributed to the model of 5 factors (13). These domains include the analysis of factors in lingual concepts, the relationship between the questionnaires of predisposition with other questionnaires and scales of evaluation, and the analysis of the genetic characteristics of personality.

Feasible points of the big 5 factors theory

Researchers, who focus on the effect of predisposition factors in personality, recognize that human behavior is not only complicated but also influenced by predisposition. Reviewing the literature, Pervin (1993) concluded that there are three different hypotheses - offshoots regarding the model of 5 factors (5). a) The basic lingual hypothesis, supporting that all important personal differences will be ascertained by studying and decoding the human language (14). b) The hypothesis that environment is determinant to personal development, supporting at the same time that the environmental effect does not influence at the same degree the members of a specific family $(6,15)$. c) The hypothesis based on the evolutionary theory, which supports the genetic predisposition so as to solve the problems of the theory $(1,16)$.

However, some researchers (17) support that there is a relationship between the effects of genetic, physiology and evolutionary hypotheses. This theory moves in the domain of psychology, personality and biology, and has probably the potential to add enough elements to future research efforts on human behavior. McCrae and Costa (1997) claim that personality is significantly determined by genes, is inherited, and it is not significantly affected by the environment or nurture $(4,18)$. Moreover, Jacob et al. (2005) revealed that a diverse gene is relevant to neuroticism (19), while other researchers have already found a gene relevant to extraversion $(19,20)$.

Unfeasible points of the big 5 factors theory

Some researchers support that it is feasible to describe an individual's personality by using less than 5 factors (8). Others claim that more factors are needed, approximately 7 (such as honesty and dependence or readiness for risk taking), in order to evaluate reliably the meaning of personality $(11,21)$. Pervin (1993) who studied relative theorists of personality $(3,16)$, concluded that many researchers studying predisposition characteristics claim that personality consists of more than 5 important factors, such as selfimage, self-perception, cognitive styles and unconscious (5).

In addition, there is great thoughtfulness and hesitation regarding the ability of people to describe reliably and validly themselves on selfevaluation questionnaires (9). Furthermore, when the sample of the examined participants derives from various populations, then, it is obvious, that both the assessment and the evaluation of these factors are difficult to measure (12).

The model of 5 basic factors is focused on the stability of personality hence it does not allow discussion regarding the possibilities and the ways of personality change. Also, the denomination of the big 5 factors is not a common belief by all researchers. On one hand, they all accept extraversion and neuroticism, but on the other hand they disagree regarding the denomination of the rest 3 factors. Especially, 
there is a strong discrimination among researchers concerning openness to experience, as this factor incorporates concepts regarding culture, autonomy, intensity, ideas and principles $(8,11,21)$.

\section{Personality and athletics}

In the past, studying athletes' personality was one of the main areas of research by many scientists (22). Initially, personality researchers strived to ascertain the effect of sport participation on personality levels. However, due to methodological restrictions such as small samples, evaluation of participation only in one sport and type 1 errors, the studies finally redirected into other theoretical frames, such as ways in which personality affects the motivation of a person to participate in sports $(22,23)$.

Nevertheless, more and more researchers develop new ways to evaluate personality such as the big 5 factors model (24). Hence, relative research in sports has not investigated this model in depth yet. According to Kane (1978), there is a type of athletic personality, which differs from the general population in specific features, characterized by leadership abilities, socialization, self-confidence, social status, low levels of stress, high emotional stability, non autocratic behavior and resistance in pain (25). According to Morgan (1980), personality characteristics are able to explain athlete's performance at $20 \%$ to $45 \%$ and along with other theoretical approaches they predict behavior (26). Furthermore, Garland and Barry (1990) found that personality factors such as emotional stability, dependence on the team and preparation for hardness, are able to predict performance of high level college football players (27). Also, the results of the Piedmont, Hill, and Blanco (1999) study applying the model of big 5 factors to predict athletic performance, revealed that neuroticism and consciousness are significantly related to athletic performance (28).

In other studies conducted, they recorded minor -if any-personality changes especially when participants were children (more stable emotionally and extravert). Consequently, one cannot claim that these changes are due to sport participation or age and maturation process from childhood to adolescence $(23,29,30-32)$.

Anxiety and sports
In theory, especially in sports, anxiety is separated into trait anxiety and state anxiety, as well as, into cognitive and somatic anxiety (33).

Trait anxiety, a stable characteristic of personality, is an important factor in the sport domain. It is a fact and often obvious in everyday practice, when male and female athletes doubt about their ability level, self and succession in a game or not. According to many researchers, anxiety influence in a negative way the performance of an athlete during the game (34). Theodorakis, Goudas, and Papaioannou (2001) support that two factors are responsible for the presence of anxiety in sports, the uncertainty regarding the outcome and the importance of the outcome as perceived by the athlete (35).

Uncertainty regarding the outcome is further determined by four factors: a) whether there is a specific criterion according to which athletes judge their performance. b) The ability to appreciate their abilities accurately. c) The ability to evaluate the fact that their performance is in accordance with their abilities. d) Whether they believe that their performance will define the outcome of the game (36).

Another significant factor, responsible for the presence of anxiety for both male and female athletes, is reduced self-confidence. In cases that athletes doubt about their abilities and performance during a game, they are vulnerable to anxiety appearance. According to Yan Lan and Gill (1984), and Krane, Williams, and Feltz (1992), there is an interactive negative relationship between self-confidence and cognitive and somatic anxiety prior games (37,38). As Samulski (1987) noted, athletes feel anxiety due to several reasons (39). These include inadequate preparation, expected anticipations, presence of a strong opponent, disappointment after defeat, danger of injury, new and unfamiliar circumstances, and the relationships developed between players as well as their effect on the team.

In the present study the relationship between trait anxiety and the remainder factors of personality was selected for examination, bearing in mind that trait anxiety is important for volleyball players as it contributes to their performance and composes a relatively stable characteristic. Furthermore, there is a lack of 
research especially in volleyball sport examining the connection between anxiety and personality.

The purpose of the present study was to examine the relationship of trait anxiety and personality between male and female volleyball players as well as the relationship between trait anxiety and the remainder factors of the questionnaire describing the big 5 factors, both in the overall sample of the participants and between male and female volleyball players.

\section{MATERIALS AND METHODS}

Participants. The sample consisted of 79 volleyball athletes (35 men, 44 women). The mean age was 24.94 years for men $(\mathrm{SD}=3.71)$ and 19.27 years for women $(\mathrm{SD}=4.39)$. All male volleyball athletes participated in the $\mathrm{C}$ National Divisionchampionship, while female athletes participated in A1, A2 and B National Divisionsin Greece.

\section{Instruments}

International Personality Item Pool. The IPIP questionnaire $(14,40,41)$ was selected in order to evaluate the below 5 basic personality factors: 1) extraversion, 2) agreeableness, 3) consciousness, 4) emotional stability neuroticism, and 5) intellectual ability imagination. The questionnaire consists of 50 questions. Reliability of factors (Cronbach's alpha values), ranges from $a=.79$, for the factor consciousness, to $\mathrm{a}=.87$, for the factor extraversion (42), while retest reliability, factor structure, and convergent and discriminate validity have been further proven (43). In this study, Cronbach's alpha values ranged from .72, for intellectual ability - imagination, to .81 , for emotional stability. As mentioned by Tsaousis and Nikolaou (2001), the Greek version of IPIP has very good psychometric characteristics (44). However, it still remains to examine the structure validity of the questionnaire for the Greek population through confirmatory factor analysis. Examples regarding the questions that evaluate each factor include: 'I am the life of the party' for extraversion, 'I feel little concern for others' for agreeableness, 'I am always prepared' for consciousness, 'I am easily stressed' for emotional stability - neuroticism and 'I have a rich vocabulary' for intellectual ability - imagination. Responses were given at a
5 point Likert typescale, rangingfrom 1(disagree) to 5(agree).

Trait Anxiety Questionnaire. State - Trait Anxiety instrument consists of 20 questions that evaluate general trait anxiety as a stable characteristic of personality that is assumed as an attribute, an aptitude or a tendency of a person (45). High levels in the above scale are noticed for those who tend to receive and interpret social situations as more threatening, as well as, to react with intensity in difficult situations. Cronbach's alpha values for the trait anxiety scale (e.g. 'I feel pleasantly') in Greek populations ranges from .84 to .86 , while its validity has already been proven $(46,47)$. Participants were called to answer at a 4 point Likert type scale, ranging from 1 (almost never) to 4(almost always).

Procedure. Questionnaires were distributed to male and female athletes in volleyball courts after the end of their training, with total time needed to complete the questionnaire ranging from 15 to 25 minutes. Research participation of the volleyball athletes was voluntary and questionnaires were anonymous and confidential.

Statistical Analysis. Statistical analysis was conducted using the 19.00 SPSS version and included Cronbach's $\alpha$ reliability analysis and components' correlation using Pearson's r. Differences between genders of the participants (males-females) and age differences were analyzed using t-test for independent samples and One-way ANOVA. Significance level was set at $5 \%(\mathrm{p}<0.05)$.

\section{RESULTS}

Descriptive statistics of trait anxiety and personality factors between male and female volleyball players is shown in Table 1. The results showed statistical significant differences for extraversion $\mathrm{t}=-2.17, \mathrm{df}=77, \mathrm{p}=0.033$, agreeableness $\mathrm{t}=-4.02, \mathrm{df}=77, \mathrm{p}=0.001$, and emotional stability $\mathrm{t}=-2.16, \mathrm{df}=77, \mathrm{p}=0.034$ factors. No statistical significant differences were noticed between male and female volleyball athletes for trait anxiety, consciousness and intellectual ability imagination. It seems that male participants exhibit less extraversion and agreeableness but 
show more emotional stability compared to female volleyball players.

Using the age differences pattern according to Donnellan and Lucas, (2008) (e.g. 15-19 years old, 20-29 years old and 30-39 years old) (48), no statistical significant differences were observed between the above mentioned age ranges or between each gender separately using one-way ANOVA with Bonferroni adjustment.

\begin{tabular}{|c|c|c|c|}
\hline Factors & $\begin{array}{c}\text { Mean \&SD } \\
(\mathrm{N}=79)\end{array}$ & $\begin{array}{c}\text { Mean \&SD } \\
\text { MEN (N=35) }\end{array}$ & $\begin{array}{c}\text { Mean \&SD } \\
\text { WOMEN }(\mathrm{N}=44)\end{array}$ \\
\hline Trait Anxiety & $38.41 \pm 8.11$ & $37.62 \pm 7.35$ & $39.05 \pm 8.71$ \\
\hline Extraversion & $34.23 \pm 9.72$ & $31.63 \pm 6.84$ & $36.30 \pm 11.16$ \\
\hline Agreeableness & $41.30 \pm 6.02$ & $38.51 \pm 6.78$ & $43.52 \pm 4.23$ \\
\hline Consciousness & $36.24 \pm 6.96$ & $34.86 \pm 6.87$ & $37.34 \pm 6.91$ \\
\hline Emotional Stability & $29.75 \pm 7.91$ & $31.86 \pm 7.84$ & $28.07 \pm 7.63$ \\
\hline Intellectual Ability - Imagination & $37.03 \pm 5.83$ & $37.14 \pm 5.89$ & $36.93 \pm 5.85$ \\
\hline
\end{tabular}

The relationship between personality and trait anxiety factors were examined initially for all participants of the study as a whole (Table 2) and then for male and female volleyball athletes separately (Table 3). Correlation analysis Pearson $r$ was applied to determine the relationship among the examined factors. Results showed a strong negative relationship between trait anxiety and emotional stability $(r=-.66, p<$ $.001)$, and a negative linear relationship between trait anxiety and intellectual ability imagination $(r=-.34, p<.001)$. The factor extraversion was found to be positively related to social acceptable behavior $(r=.24, p<.05)$ and intellectual ability - imagination $(r=.26, p<$ $.05)$. Agreeableness $(r=.24, p<.05)$, consciousness $(r=.30, p<.05)$ and emotional stability $(r=.23, p<.05)$ were all factors positively related with intellectual ability imagination.

Correlation results between personality and trait anxiety tfactors of for male and female volleyball players separately (Table 3 ), revealed trait anxiety as negatively associated with the factors of emotional stability $(r=-.70, p<.001)$ and intellectual ability - imagination $(r=-.56$, $p<$,001) for male athletes. As for female athletes, a strong negative linear relationship was only noticed between trait anxiety and emotional stability factors $(r=-.64, p<.001)$. Agreeableness was positively associated with emotional stability for male athletes $(r=.45, p<$ $.001)$, while for female athletes, a negative linear relationship between agreeableness and emotional stability was noted but to the extent it was statistically significant. Moreover, agreeableness was positively associated with intellectual ability - imagination $(r=.43, p<$ $.001)$ for female athletes, while no relevant linear relationship for male volleyball athletes was noticed. Finally, the factor consciousness was positively associated with intellectual ability - imagination only for male athletes $(r=.43, p<$ $.05)$ while there was not a relevant linear relationship recorded for female volleyball athletes.

Table 2. Correlation of factors for male and female volleyball athletes as a whole $(\mathbf{N}=79)$

\begin{tabular}{lcccccc}
\hline \multicolumn{1}{c}{ Factors } & 1 & 2 & 3 & 4 & 5 & 6 \\
\hline 1. Trait anxiety & - & -.16 & -.02 & -.17 & $-.66^{* *}$ & $-.34^{* *}$ \\
2. Extraversion & & - & $.24 *$ & .00 & .09 & $.26^{*}$ \\
3. Agreeableness & & & - & .10 & .04 & $.24^{*}$ \\
4. Consciousness & & & & - & .13 & $.30^{*}$ \\
5. Emotional Stability & & & & & - & $.23^{*}$ \\
6. Intellectual Ability - Imagination & & & & & & - \\
\hline$* p<.05, * * p<.001$ &
\end{tabular}


Table 3. Correlation of the factors for male and female volleyball athletes separately

\begin{tabular}{lcccccc}
\hline \multicolumn{1}{c}{ Factors } & 1 & 2 & 3 & 4 & 5 & 6 \\
\hline 1. Trait anxiety & - & -.34 & -.18 & -.29 & $-.70^{* *}$ & $-.56^{* *}$ \\
2. Extraversion & -.14 & - & .25 & -.24 & .14 & .31 \\
3. Agreeableness & .05 & .11 & - & .01 & $.45^{* *}$ & .16 \\
4. Consciousness & -.13 & .05 & .06 & - & .16 & $.43^{*}$ \\
5. Emotional stability & $-.64 * *$ & .17 & -.22 & .19 & - & .32 \\
6. Intellectual ability - imagination & -.20 & .26 & $.43^{* *}$ & .21 & .17 & - \\
\hline Correlation is about male athletes over the diagonal and female athletes below the diagonal, ${ }^{*} p<.05, * * p<.001$
\end{tabular}

\section{DISCUSSION AND CONCLUSION}

Overall, the results of this study did not reveal statistically significant differences between male and female volleyball athletes concerning trait anxiety, consciousness and intellectual ability - imagination. On the contrary, statistically significant differences were found between male and female athletes as regards to extraversion, agreeableness, and emotional stability factors. It appears that male athletes as compared to female athletes appear less extraverted. That is less cordial and social and they search to a lesser degree for emotions regarding sport and activity. Furthermore, they appear more stable emotionally, with less anxiety, aggression and emotions of sadness, shyness and impulsivity while demonstrating less agreeableness caring less to be likeable and attractive (8).

Extraversion, together with agreeableness, can be used to describe the two dimensions of the interpersonal circumflex (49), which contains descriptions of traits relevant to interpersonal interaction. Given the importance of extraversion to the interpersonal domain as it relates to dominant contains traits such as bossy, domineering, and assertive, women as expected in this study consistently scored higher than men, with the specific traits measured fall closer to the 'dominance pole' (50).

The statistically significant differences observed for 'extraversion' and 'emotional stability - neuroticism' factors may also be related with the different competition level in agreement with Maynard et al. (1995), who noted that high level athletes demonstrate high 'extraversion' scores (34). The level of the female participants playing at A1, A2 and B National Division was definitely higher than the level of male athletes who played for $\mathrm{C}$ National
Division. In this regard, McKelvie, Lemieux, and Scout (2003), also support the notion that high level athletes are less neurotic and more extraverted compared to low level athletes (51).

Furthermore, gender differences in agreeableness may be related to gender differences in self-construal. According to Markus and Kitayama (1991), men tend to portray an independent self-construal sense of self that is separate from cognitive representations of others whereas women show a more interdependent identity in which their sense of self includes significant others (52). This gender difference is associated with motivational and behavioral differences, since women have the tendency to interconnect with social groups (53). Therefore, they may be more motivated than men to maintain social and emotional bonds by enacting more agreeable traits. No statistical significant differences were observed according to the age range of participants, in agreement with Donnellan and Lucas (2008) stating that neither gender nor education level were consistent moderators of age differences in the Big Five concept (48).

Another important conclusion emerged, is the negative relationship observed between trait anxiety with emotional stability and intellectual ability - imagination. This is similar to the case of Maynard et al. (1995), supporting that athletes' ability to control anxiety depends more on the 'emotional stability - neuroticism' factor than the 'extraversion' factor (34). Trait anxiety, which is an attribute and an aptitude of a person, is the reason that high level male and female volleyball athletes tend to realize situations as more threatening compared to others. Their tendency to react with anxiety and intensity on difficult situations is negatively associated with aggression, vulnerability and impulsiveness, as 
well as with their cognitive skills and the educational level of both male and female athletes. Extraversion was positively correlated at a low degree with agreeableness and intellectual ability - imagination. Cordiality, confidence, research of emotions, are values that affect -and are affected- by the agreeableness male and female volleyball athletes demonstrate, the satisfaction they feel during participation in sports, and probably their educational level.

Agreeableness, consciousness and emotional stability are all values also showed to exhibit low positive correlation with intellectual ability imagination (54). Sociability, social activity behavior and feelings that male and female volleyball athletes both receive and externalizeis positively associated with openness to experience due to team participation. The deep sense of duty and eagerness athletes demonstrate during training and official games, deriving from their commitment to participation in sport are not only positively associated but also affect and are affected by their intellectual ability and imagination (50). Anxiety control, aggression, vulnerability and impulsiveness are also factors influenced by their intellectual ability to handle situations.

A main conclusion emerged from the present study is the discrimination noted between the factors of personality and gender of participants. In addition, there was a discrimination regarding the results of correlation analysis between the factors of personality and trait anxiety, in cases that gender was considered a criterion.

The practical implication of this study is directly connected with everyday volleyball coaching. Since women players are more sociable but less emotionally stable the coach should focus more on developing a good climate and cohesion of the team whereas in male volleyball teams coaches should focus more on task and maximization of individual performance and less on social context.
Results of the present study are limited to volleyball and team sports only. Consequently, research on individual sports is needed to further investigate any essential differences. Further researches using larger samples and applying additional instruments which are more sensitive to describe individual personality differences should also be developed. In addition intercultural differences should also be taken into account to identify possible and investigate further the relationship of personality with other factors such as encouragement and athletic acknowledgement.

Personality scores used in our investigation were obtained via self-report. Thus, our findings indicate gender differences in how men and women volleyball players perceive themselves, but do not necessarily reflect how they are perceived by others concerning their actual behavioral tendencies. Future research should therefore explore gender differences in peerreports of these personality traits. Additionally, behavioral or implicit measures of personality could be used to investigate whether the same pattern of gender differences exist when researches shift beyond measuring personality through questionnaires (50).

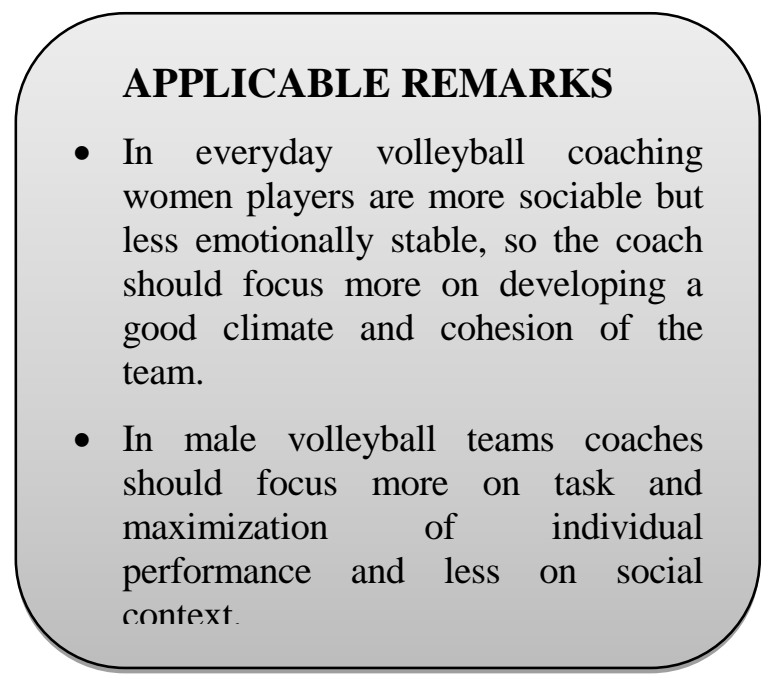

\section{REFERENCES}

1. Tooby J, Cosmides L. On the universality of human nature and the uniqueness of the individual: The role of genetics and adaptation. Journal of Personality. 1990; 58: 17-67.

2. Costa PTJr, McCrae RR. Stability and change in personality assessment: the revised NEO Personality Inventory in the year 2000. Journal of Personality Assessment. 1997; 68(1): 86-94.

3. McAdams DP. What do we know when we know a person? Journal of Personality. 1995; 63:365-396. 
4. McCrae RR, Costa PTJr. Personality trait structure as a human universal. American Psychologist. 1997; 52: 509516.

5. Pervin LA. Persönlichkeitstheorien. München: Ernst Reinhardt Verlag; 1993.

6. Plomin R. The role of inheritance in behavior. Science. 1990; 248: 183-188.

7. Norman WT. Toward an adequate taxonomy of personality attributes: Replicated factor structure in peer nomination personality ratings. Journal of Abnormal and Social Psychology. 1963; 66: 574-583.

8. Digman JM. Higher order factors of the Big Five. Journal of Personality and Social Psychology. 1997; 73: 12461256.

9. Saucier G, Georgiades S, Tsaousis I, Goldberg RL. The Factor Structure of Greek Personality Adjectives. Journal of Personality And Social Psychology. 2005; 88(5).

10. Tsaousis I, Kerpelis P. The Traits Personality Questionnaire 5 (TPQue5): The psychometric evaluation of a shortened version. European Journal of Psychological Assessment. 2004; 20(3): 180-191.

11. Becker P, Kupsch M.. The four-plus-X factor model for the description of normal and disordered personality as an alternative to the five-factor model: A test of two models. Trierer Psychologische Berichte. 2002; Band 29, Heft 6.

12. Block J. A contrarian view of the five-factor approach to personality description. Psychological Bulletin. 1995; 117: $187-215$.

13. Hofstee WKB, De Raad B, Goldberg LR. Integration of the Big Five and circumplex approaches to trait structure. Journal of Personality and Social Psychology. 1992; 63: 146-163.

14. Goldberg LR. An alternative description of personality: The Big-Five factor structure. Journal of Personality and Social Psychology. 1990; 59: 1216-1229.

15. Plomin R, Daniels D. Why are children in the same family so different from one another? Behavioral and Brain Sciences. 1987; 10: 1-60.

16. Buss DM. Sex differences in human mating: Evolutionary hypotheses tested in 37 cultures. Behavioral and Brain Sciences. 1989; 12: 1-49.

17. Watson D, Weise D, Vaidya J, Tellegen A. The two general activation systems of affect: Structural findings, evolutionary considerations, and psychobiological evidence. Journal of Personality and Social Psychology. 1999; 76: 820-838.

18. Ahmed MM, Galal El-Din, Nagwa Hassan Ali, Hamdy Hamed Swelim, Khalda Said Amr, and Laila Kamal ElDin Effat. Monoamine oxidase A (MAOA) gene polymorphism in offenders and psychiatric patients in an Egyptian Study. IOSR Journal of Pharmacy and Biological Sciences (IOSR-JPBS). 2014;9(2): 38-42.

19. Jacob CP, Müller J, Schmidt M, Hohenberger K, Gutknecht L, Reif A, Schmidtke A, Mössner R, Lesch PK. Cluster B Personality Disorders are Associated with Allelic Variation of Monoamine Oxidase A Activity. 2005; Available from: Neuropsychopharmacology, doi:10.1038/sj.npp.1300737.

20. Montag C. The Brain Derived Neurotrophic Factor and Personality. Advances in Biology. 2014; Article ID 719723. doi:10.1155/2014/719723.

21. Ashton MC, Lee K, Perugini M, Szarota P, De Vries RE, Di Blas L. A six - factor structure of personalitydescriptive adjectives: Solutions from psycholexical studies in seven languages. Journal of Personality and Social Psychology. 2004; 86: 356-366.

22. Eysenk HJ, Nias DK, Cox DN. Sport and personality. Advances in Behaviour Research and Therapy. 1982; 4: 1 56.

23. Vealey RS. Personality and Sport Behavior. In: Horn T, editor. Advances in Sport Psychology. Champaign, IL: Human Kinetics; 2002. 2nd edition: pp. 43-82.

24. Digman JM. Personality structure: Emergence of the five-factor model. Annual Review of Psychology. 1990; 41: 417-440.

25. Kane JE. Persons, Situations and Performance. In: Glengross DJ, editor. Psychology and Sport. Sydney: McGraw Hill; 1978.

26. Morgan WP. Trait psychology controversy. Research Quarterly for Exercise and Sport. 1980; 51: 50-76.

27. Garland JK, Barry JR. Personality and leader behaviors in collegiate football: a multidimensional approach to performances. Journal of Research in Personality. 1990; 24:355-370.

28. Piedmont RL, Hill DC, Blanco S. Predicting athletic performance using the five-factor model of personality. Personality and Individual Differences. 1999; 27: 769-777.

29. Folikins CH, Sime WE. Physical fitness training and mental health. American Psychologist. 1981; 36(4): 373 389.

30. Gruber JJ. Physical activity and self- esteem development in children: A meta - analysis. American Academy of Physical Education Papers. 1986; 19: 30-48. 
31. Sonstroem RJ. Exercise and self - esteem. In: Dishmann RK, editor. Exercise adherence: Its impact on public health. Champaign, IL: Human Kinetics; 1984. pp. 125-153.

32. Sonstroem RJ, Morgan WP. Exercise and self - esteem.: Rationale and Model. Medicine and Science in Sports and Exercise. 1989; 21(3): 329-337.

33. Martens R, Gill DL. State anxiety among successful and unsuccessful competitors who differ in competitive trait anxiety. Research Quarterly. 1976; 47: 698-708.

34. Maynard IW, Hemmings B, Warwick-Evans L. The effects of a somatic intervention strategy on competitive state anxiety and performance in semiprofessional soccer players. The Sport Psychologist. 1995; 9: 51-64.

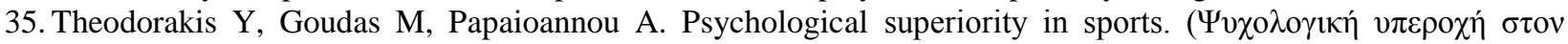

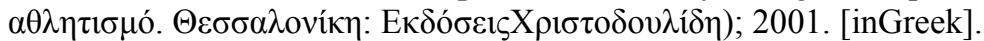

36. Martens R, Vealey RS, Burton, D. Competitive anxiety in sport. Champaign IL: Human Kinetics; 1990.

37. Yan Lan L, Gill DL. The relationships among self-efficacy, stress responses, and a cognitive feedback manipulation. Journal of Sport Psychology. 1984; 6: 227-238.

38. Krane V, Williams J, Feltz D. Path analysis examining relationships among competitive anxiety, somatic anxiety, state confidence, performance expectations, and golf performance. Journal of Sport Behavior. 1992; 15: 279-295.

39. Samulski D. Wie motivieren sich Leistungssportler selbst? In Münster: Leistungspsychologie. 1987; 1: 7 - 11.

40. Goldberg LR. The development of markers for the Big-Five factor structure. Psychological assessment. 1992;4:126. http://dx.doi.org/10.1037/1040-3590.4.1.26.

41. International Personality Item Pool (2001). A Scientific Collaboratory for the Development of Advanced Measures of Personality Traits and Other Individual Differences. Available from: http://ipip.ori.org/. Internet Website.

42. Goldberg LR. A broad-bandwidth, public domain, personality inventory measuring the lower-level facets of several five-factor models. In: Mervielde I, Deary I, De Fruyt F, Ostendorf F, editors. Personality Psychology in Europe. 1999; Vol. 7: 7-28.

43. John OP, Srivastava S. The Big Five trait taxonomy: History, measurement, and theoretical perspective. In: Pervin LA, John OP, editors. Handbook of personality: Theory and research. New York: Guilford Press ; 1999. 2nd edn, pp. 102139.

44. Tsaousis I, Nikolaou I. The Stability of the Five -Factor Model of Personality in Personnel Selection and Assessment. International Journal of Selection and Assessment. 2001; 9: 290-301.

45. Laux L, Glanzmann P, Schaffner P, Spielberger CD. State-Trait Angstinventar (STAI). Wien: Psychologisches Institut; 1981.

46. Kakkos B, Ekkekakis P, Zervas I. Psychometric proportions of state-trait anxiety questionnaire (STAI) in Greek population. SportsPsychology. 1991;5: 3-34. [in Greek].

47. Liakos A, Giannitsi S. Reliability and Validity of the modified Spielberger's State-Trait Anxiety Inventory in Greek population. Egefalos. 1984; 21: 71-76.

48. Donnellan MB, Lucas RE. Age Differences in the Big Five Across the Life Span: Evidence from Two National Samples. Psychology and Aging. 2008; 23(3): 558-566. http://doi.org/10.1037/a0012897.

49. Gurtman MB. Exploring Personality with the Interpersonal Circumplex. Social and Personality Psychology Compass. 2009; 3: 601-619. DOI: 10.1111/j.1751-9004.2009.00172.x

50. Weisberg YJ, DeYoung CG, Hirsh JB. Gender Differences in Personality across the Ten Aspects of the Big Five. Frontiers in Psychology. 2011; 2: 178. http://doi.org/10.3389/fpsyg.2011.00178.

51. McKelvie SJ, Lemieux P, Stout D. Extraversion and Neuroticism in Contact Athletes, No Contact Athletes and Non-athletes: A Research Note. Athletic Insight. 2003; 5: 3.

52. Markus HR, Kitayama S. Culture and the self: Implications for cognition, emotion, and motivation. Psychological Review. 1991; 98(2): 224-253.

53. Schmitt DP, Realo A, Voracek M, Allik J. Why can't a man be more like a woman? Sex differences in Big Five personality traits across 55 cultures. Journal of Personality and Social Psychology. 2008; 94(1): 168-182. http://dx.doi.org/10.1037/0022-3514.94.1.168.

54. Fayombo G. The Relationship between Personality Traits and Psychological Resilience among the Caribbean Adolescents. International Journal of Psychological Studies. 2010; 2(2):105-116. www.ccsenet.org/ijps 